\title{
Improving resuscitation skills in psychiatric hospitals
}

\author{
A multidimensional problem
}

\author{
Tony Winston and Gary Drybala
}

There is currently concern that junior psychiatrists lack
adequate skill in cardiopulmonary resuscitation.
However, little altention has been given to the equally
important issues of nurse training, organisation and the
provision of equipment and drugs which are
appropriate to psychlatic wards. This paper describes
the work of the Leicestershire Mental Health Services
Resusctiotion Commiltee and makes suggestions as to
how these problems may be capproached.

There is increasing awareness of the fact that trainee psychiatrists often lack adequate skills in basic and advanced life support, and concern has been expressed about this recently (Kosky \& Spearpoint, 1993; McNaughton et al, 1994). This concern is likely to grow as mental health services are increasingly provided by independent trusts without access to general hospital facilities and mental health trusts will have to consider whether their current resuscitation standards can be considered adequate.

The Leicestershire Mental Health Services NHS Trust is one of the largest mental health trusts in the country and until recently included two large, old psychiatric hospitals as well as a unit based on a general hospital site and a number of smaller community units. A second general hospital unit opened in 1996 . We have become increasingly aware in Leicestershire of the need to improve our standard of resuscitation practice and the Trust has attempted to address this by establishing a resuscitation committee, whose remit includes setting up a comprehensive training programme for both medical and nursing staff, recommendations for up-to-date equipment standardised across the Trust. the establishment of effective operational procedures, and audit.

We assume that other mental health trusts face similar difficulties to ours; this paper describes our approach to the problem and some of the obstacles we encountered. We do not claim to have resolved all the difficulties in a complex situation but hope that our experience will prove helpful to clinicians elsewhere.

\section{Establishing a resuscitation committee}

The initial membership of the committee consisted of a consultant psychiatrist, a junior psychiatrist with previous experience in general medicine and Accident and Emergency (A\&E), a senior nursing manager and a general manager. We decided to keep the committee small in order to facilitate effective working and allow frequent meetings. We sought the input of a number of external advisers including the resuscitation training officer from a local general hospital, a charge nurse from the local A\&E department and a consultant anaesthetist. Their contributions proved invaluable.

We experienced a number of initial difficulties in attempting to establish core standards of equipment and practice, resulting from a low level of basic knowledge among staff, lack of standardisation of equipment across sites and inconsistencies in emergency procedures.

In addition, we felt that a culture of learned helplessness' had evolved in which both medical and nursing staff were aware of their outdated or inadequate training in this area but felt unable to do anything about it.

We concentrated on four key areas: training of junior medical staff; training of nursing staff; provision of appropriate and standardised equipment; and organisation.

\section{Training of junior medical staff}

It is well recognised that junior medical staff working in general hospitals often perform badly in the practical skills required for cardiopulmonary resuscitation (Royal College of Physicians, 1987). This is probably even more true for trainee psychiatrists who are only infrequently exposed to cardiac arrests and for whom formal training is rarely provided. Trainees in Leicestershire were very aware of their deficiencies in this area and had already requested further training. We therefore instituted a rolling programme of six- 
monthly training sessions in basic and advanced life support, provided initially by the resuscitation training officer of a local general hospital. These sessions were specifically tailored to the requirements of junior doctors working in isolation in psychiatric hospitals. Specific instruction was given in emergencies which are particularly common in psychiatric hospitals, such as choking and self-strangulation.

Attendance at early training sessions was poor and sessions were therefore made mandatory with the agreement of the local training committee. Attendance is now documented in trainees $\log$ books and trainees were asked to provide feedback on the relevance of the sessions to their needs.

\section{Nurse training}

In most cases of cardiac or respiratory arrest the first person on the scene will be a member of the nursing staff and there may be a considerable delay before the doctor arrives. It is generally agreed that adequate basic life support needs to be instituted within the first three minutes after cardio-respiratory arrest and it is therefore essential that nursing staff are able to carry this out satisfactorily. Surprisingly, therefore, instruction in basic life support does not appear to be recognised in the continuing education of psychiatric nurses. We found that nursing staff shared with junior medical staff an awareness of their inadequate training in this area and often felt anxious and helpless when confronted with a collapsed patient.

In addition to basic life support skills, psychiatric nurses also need to know how to assist medical staff when a cardiac arrest occurs. This requires familiarity with the equipment and drugs needed in advanced life support and instruction on this was therefore included in the training sessions for nursing staff. As with the junior doctors, training was geared to the particular needs and experience of those working in a psychiatric setting. Having recognised the need eventually to train all nursing staff, we realised that certain groups of nursing staff needed to be given priority.

Staff working in electroconvulsive therapy units and acute admission wards (including elderly assessment wards) were given the greatest priority and those working in the community the least. Trained staff will be offered regular refresher sessions at six-monthly intervals.

\section{Equipment}

The provision of appropriate emergency medical equipment for a large psychiatric hospital requires considerable thought and attempts simply to transplant a standard cardiac arrest trolley from a general hospital are likely to be inappropriate. Psychiatric hospitals may be old and large and equipment may need to be transported over considerable distances. In some circumstances, it may need to be carried up and down stairs, or even from one building to another. We found the Resus Positive Crash Box (Resus Positive Limited, Rochester, Kent), a light-weight plastic case with carrying strap, to be suitable for use in this situation and large enough to include an adequate range of equipment. Following discussion with colleagues in Anaesthetics and $A \& E$, we drew up a list of advanced resuscitation equipment which can be carried in the crash box and which we feel should be adequate for advanced life support, pending the arrival of an ambulance (Box 1). This is supplemented by a portable defibrillator and a light portable electrical suction unit. Wards in the general hospital units continue to use conventional wheeled trolleys.

Audit of equipment already in use within the Trust revealed three different types of defibrillator, each requiring separate instruction for staff. The resulting difficulties emphasised the need for coordinated purchasing of equipment so as to ensure standardisation across the Trust.

We also made recommendations about basic equipment which should be available on every ward (Box 2). This included the advice that all wards should be equipped with at least one and preferably two Laerdal pocket masks and that these should be easily available, for example in the ward office. This simple device provides an effective means of ventilating the patient as a first aid measure and is considerably easier for the untrained operator to use than a bag and mask. It also includes a one-way valve and therefore protects the operator from the hazards of infection from contact with the patient's body fluids.

We also prepared, in conjunction with our pharmacy, a list of emergency drugs to be held on every ward (Box 3). These are divided into drugs required for cardiac arrest and drugs required for other medical emergencies.

Implementation of the equipment policy proved complex and considerably more timeconsuming than we had anticipated. An initial audit showed that in many units there was no established procedure for the checking, replacement or maintenance of emergency medical equipment. We therefore made it an immediate priority to set up an appropriate contract with the medical physics department of a local general hospital to ensure that essential equipment such as defibrillators was serviced regularly. Large quantities of obsolete equipment had to be removed from many wards and staff familiarised with the more up-to-date equipment. 


\section{Box 1. Advanced resuscitation equipment}

Cotton wool balls

Tourniquet

Bag and mask (sizes 4 and 5), with reservoir

\section{and valve}

Laryngoscopes, curved blade $\times 2$

Catheter mounts

Bandage

K-Y Jelly

Scissors

Artery clip

Resuscitation drug boxes

Suction catheters

Yankauer suckers

Normal saline - 1 litre

Haemaccel $-500 \mathrm{ml} \times 2$
Blood giving sets $\times 2$

Defibrillation pads

Disposable razors

Normal saline $10 \mathrm{ml}$ ampoules

Gloves

Nebuliser mask

Cuffed endotracheal tubes, sizes 7.5,8.0,8.5,9.0

Guedel airways - sizes 2,3,4

Syringes (Luer Lock) $2 \mathrm{ml}, 5 \mathrm{ml}, 10 \mathrm{ml}, 20 \mathrm{ml}$

Needles $-25 \mathrm{~g}, 23 \mathrm{~g}, 21 \mathrm{~g} .19 \mathrm{~g}$

Oxygen tubing

Venflons $-20 \mathrm{~g}, 18 \mathrm{~g}, 16 \mathrm{~g}, 14 \mathrm{~g}$

Defibrillator

ECG electrodes and self adhesive pads

Portable electrical suction apparatus

\section{Box 2. Basic resuscitation equipment}

Bag and mask (sizes 4 and 5) with reservoir and valve

Guedel ainways - sizes 2,3,4

Laerdal pocket mask $\times 2$

Oxygen cylinder

Oxygen tubing

Face masks $24 \%$ and $60 \%$

Drip stand

Laerdal V-Vac suction unit

Yankauer suckers
Members of the resuscitation committee at first attempted to carry out these tasks themselves. but it soon became apparent that this was impractical and it was therefore decided to appoint an appropriately qualified nurse in each in-patient unit to take responsibility for the distribution and checking of equipment.

\section{Organisation and audit}

Cardiac arrests in psychiatric hospitals are, fortunately, rare, but this may mean that the procedure for summoning help is complicated or unclear. Clear-cut, written procedures need to be

Box 3. Emergency drugs

Cardiac arrest drugs

Adrenaline $1: 10,0001 \mathrm{mg} / 10 \mathrm{ml}$ minijet

Atropine sulphate $1 \mathrm{mg} / 10 \mathrm{ml}$ minijet

Calcium chloride $10 \% 1 \mathrm{~g} / 10 \mathrm{ml}$ minijet

Isoprenaline 200 micrograms $/ 10 \mathrm{ml}$ minijet

Lignocaine $2 \% 100 \mathrm{mg} / 5 \mathrm{ml}$ minijet

Naloxone $400 \mathrm{mcg} / \mathrm{l} \mathrm{ml} \mathrm{minijet}$

Non-cardiac arrest drugs

Adrenaline

Aminophylline

Chlorpheniramine

Dextrose

Glucagon

Diazepam

Diazemuls

Flumazenil

Frusemide

Hydrocortisone

Salbutamol

Sodium chloride

Water for injection

$8 \times 10 \mathrm{ml}$
$4 \times 10 \mathrm{ml}$
$1 \times 10 \mathrm{ml}$
$1 \times 10 \mathrm{ml}$
$1 \times 5 \mathrm{ml}$
$1 \times 1 \mathrm{ml}$

1:1000 $1 \mathrm{ml} \times 4$

$250 \mathrm{mg}$ in $10 \mathrm{ml} \times 2$

$10 \mathrm{mg}$ in $1 \mathrm{ml} \times 1$

$50 \%$ syringe $(50 \mathrm{ml}) \times 1$

$1 \mathrm{mg}$ injection

$5 \mathrm{mg}$ rectal tube $\times 2$

$10 \mathrm{mg}$ in $2 \mathrm{ml} \times 2$

$500 \mathrm{mcg}$ in $5 \mathrm{ml} \times 2$

$50 \mathrm{mg}$ in $5 \mathrm{ml} \times 2$

$100 \mathrm{mg}$ injection $\times 1$

$5 \mathrm{mg}$ in $2.5 \mathrm{ml}$ nebuliser solution $\times 4$

$0.9 \% 2 \times 5 \mathrm{~m}$

$2 \times 2 \mathrm{ml}$ 
drawn up and all staff (including the hospital switchboard) must be familiar with them.

Guidelines for the management of cardiac arrest (European Resuscitation Council, 1993) have been publicised throughout the Trust and educational posters have been displayed on the wards.

We recognised the importance of auditing our efforts to improve resuscitation practice, but have elected to approach this in a relatively low-key way. Staff may feel threatened or defensive if they feel that audit is being used to show up their deficiencies. We felt that this problem was best tackled by using a resuscitation audit form which emphasised potential improvements in practice rather than simply highlighting deficiencies.

\section{Puture developments: resuscitation training officer}

We encountered numerous obstacles in our attempts to purchase training from neighbouring non-mental health trusts. They understandably found it difficult to provide training for the very large number of staff (approximately 1200) in our Trust within an acceptable time period. The purchase of training on a piecemeal basis from various sources led to difficulty in organising regular training and refresher sessions and to a lack of consistency in content. Furthermore, external training failed to address the problem of equipment provision and maintenance or the organisational issues. We therefore concluded that the most appropriate way to resolve these problems was through the appointment of a fulltime resuscitation officer, based within our Trust and either employed directly or seconded on a contractual basis from another Trust. This proposal had, of course, to compete with rival bids for limited resources within the Trust. However, it was ultimately recognised by senior management that adequate resuscitation provision constituted an important element in the Trust's risk-management strategy and funding has now been made available, initially for a twoyear period.

\section{Conclusion}

The provision of adequate standards of resuscitation in psychiatric units is a matter of considerable and justifiable concern. This is likely to increase as mental health trusts become more separate from general medical services and have to take responsibility for their own standards and training.

We suggest that these concerns need to be addressed in a comprehensive and coordinated manner which also takes account of the particular needs and anxieties of staff working in psychiatric units. The establishment of a resuscitation committee, supported by appropriate expert advisers has, in our experience, proved to be an effective means of achieving this and we hope will bring considerable benefits in terms of the skill and confidence of staff and the safety of patients. It has already resulted in major changes in the provision and organisation of services within our Trust.

\section{Acknowledgements}

We thank all those who have contributed to the work of the Leicestershire Mental Health Services Resuscitation Committee and the preparation of this paper. Particular thanks are due to Frank Durning, Leicester Royal Infirmary, and Bob Williams, Leicester General Hospital, whose help has been invaluable.

\section{References}

EuRopean Resuscttation Council (1993) Guidelines for basic life support and adult advanced cardiac life support. British Medical Journal, 306, 1587-1593.

KOSKY, N. \& SPEARPOINT, K. (1993) Resuscitation skills of psychiatric trainees - a suitable case for treatment? Psychiatric Bulletin. 17, 489-491.

McNaugton, G, HALL, D. J. \& STARK. C. (1994) Resuscitation skills and doctors working in psychiatry. Psychiatric Bulletin, 18, 403-404

Royal College of PHYSicians (1987) Resuscitation from cardiopulmonary arrest: training and organisation Journal of the Royal College of Physicians, 21. 175-182.

Tony Winston, Lecturer and Honorary Senior Registrar, Academic Department of Psychiatry. Brandon Mental Health Unit, Leicester General Hospital, Leicester LE5 4PW and Gary Drybala. Consultant Psychiatrist, Leicestershire Mental Health Services NHS Trust, Brandon Mental Health Unit, Gwendolen Road, Leicester LE5 4PW

*Correspondence 